\title{
Descending thoracic aorto bifemoral artery bypass for Aortoiliac occlusive disease :A novel anterior subcutaneous tunnel approach
}

\author{
Dr. Rajendra Mohan Mathur ${ }^{1}$, Dr. Sanjeev Devagarha ${ }^{2}$, Dr. Anula Sisodia ${ }^{3}$, \\ Dr. Gaurav Goyal ${ }^{4}$, \\ ${ }^{1}$ Professor and Head of department, CardioThoracicVascular surgery, S.M.S hospital, Jaipur,Rajasthan,India \\ ${ }^{2}$ Associate Professor,CardioThoracicVascular surgery, S.M.S hospital, Jaipur, Rajasthan,India \\ ${ }^{3}$ Assistant Professor,CardioThoracicVascular surgery, S.M.S hospital, Jaipur, Rajasthan,India \\ ${ }^{4}$ Resident, CardioThoracicVascular surgery, S.M.S hospital, Jaipur, Rajasthan,India
}

\begin{abstract}
Descending thoracic aortobifemoral bypass via novel anterior subcutaneous tunnel approach was evaluated in 31 patients. Indications for this approach were; infrarenal aortic block with no site for infrarenal aortic clamping(18 cases), calcified infrarenal aorta(11 cases) and history of laparotomy(2 cases). Duration of surgery was 1.5 to 3 hours and blood loss was $300 \mathrm{ml}$ to $1000 \mathrm{ml}$. There was mortality of 2 patients. Reexploration due to bleeding was done in 3 patients and 3 patients required prolonged ventilatory support for 2 days. This approach is recommended in selected patients where conventional approach to the abdominal aorta is not feasible.

Follow up of 27 pateints had patent grafts in 24 patients and blocked grafts with no symptoms in 3 patients. 2 patients were lost to follow up.
\end{abstract}

\section{Introduction}

With the reports of Stevenson et $\mathrm{al}^{1}$ and Blaisdell ${ }^{2}$ in 1961, the use of the descending thoracic aorta as an alternative inflow source for the treatment of aortoiliac occlusive disease was introduced. Bypass grafting from the descending thoracic aorta to the iliac or femoral arteries initially was used as a remedial reconstruction for aortic graft failure, graft infection, or other intra-abdominal catastrophes. Although descending thoracic aorta to iliofemoral artery bypass grafting as a secondary reconstruction is well described, its role as a primary procedure remains controversial. Because of favorable experience with this operation for secondary reconstruction, ${ }^{3 \text { and } 4}$ the use of descending thoracic aorta to iliofemoral artery bypass grafting has been expanded in recent years to include selected patients in whom a primary conventional transabdominal approach is not feasible. Such situations include patients with severe atherosclerotic disease or complete occlusion of the infrarenal aorta, calcified aorta, history of laparotomy and with anatomic constraints that preclude a direct aortic approach. ${ }^{5}$ The usual alternatives are axillobifemoral approach and retroperitoneal descending thoracic aortic approach.

The purpose of this study was to evaluate the efficacy and safety of the anterior subcutaneous tunnel approach with thoracic aorta as an inflow source for aortoiliac revascularization.

\section{Patients And Methods}

In a 3 year period from 2010 till date, 31 patients were treated with descending thoracic aortobifemoral bypass through anterior subcutaneous tunnel approach at the Department of Cardiothoracic and vascular surgery, SMS Medical college and Hospital, Jaipur..

Age ranged from 54 to 82 years with male to female ratio of 6.7:1, symptoms ranged from intermittent claudication ( 25 cases), rest pain ( 3 cases) and non-healing ulcer ( 3 cases).

Computed Tomography Angiography( Aorta and bilateral lower limbs) was done in all patients which shows juxtarenal infraaortic block in 18 patients, calcified infrarenal aorta in 11 patients and severe stenosis in 2 patients.

Traditional transabdominal approach was not feasible due to lack of suitable site for aortic clamping in 29 patients and history of laparotomy surgery for subacute intestinal obstruction(SAIO) in 2 patients. Axillobifemoral approach was avoided to give bigger inflow vessel (aorta) and retrograde approach was avoided to make procedure less invasive and novel.

Pulmonary function tests revealed severe chronic obstructive disease(COPD) in 2 patients and mild chronic obstructive disease(COPD) in 2 patients.

Operative procedure: Standard general anesthesia with hemodynamic monitoring and double lumen endotracheal intubation was done to facilitate aortic exposure. Patient was positioned with left hemithorax lifted at angle of 45 degrees approximately and flat lower limbs for groin access. Posterolateral thoracotomy from 
sixth intercostal space was done. Dacron, Polyester and expanded-polytetraflouroethylene(e-PTFE) grafts were used for end to side proximal anastomosis to descending thoracic aorta.

A rent in anterior diaphragm was made at subxiphoid level to get the graft anteriorly with bifurcation site lying at this level, graft was then tunneled in subcutaneous tissue to groin where distal anastomosis to common femoral artery was done in end to end fashion. Thoracotomy was closed with intercostal drainage tube in situ and patients were ventilated for 4-6 hours electively. Heparin was given in dose of 5000units 8 hourly for 3 days and discharged on anticoagulants and antiplatelet drugs.

\section{Results}

Mean duration of surgery was 2.15 hours and mean blood loss was $650 \mathrm{ml}$. There was mortality of 2 patients. Both were COPD patients( 1 mild,1 severe) with intrapleural adhesions and bleed postoperatively after repair. Graft size used was $14 * 7 \mathrm{~mm}$ for males and $12 * 6 \mathrm{~mm}$ for females.Polyester,Dacron and e-PTFE grafts were used in 25 patients, 3patients and 3 patients respectively according to operating surgeon preference. Reexploration for bleeding more than $600 \mathrm{ml}$ in first 3 hours after surgery was done in 3 patients. In all three reexplored patients one patient had severe COPD while other two had mild COPD. Prolonged ventilation for 2 days were needed in all three patients.

All were extubated and behaved well postoperatively. Follow up of 27 patients showed patent grafts in 24 and blocked grafts in 3 patients with no symptoms, 2 patients were lost to follow up.

\section{Discussion}

Infrarenal aortobifemoral bypass is currently considered the gold standard for aortoiliac reconstruction in occlusive disease. When abdominal aortic surgery is contraindicated because ofsevere disease at the inflow site, axillofemoral bypass is currently the most common alternative pro-cedure. However, the results of axillofemoral bypass are generally less than ideal in terms of patency and quality of life, although some better primary patency rates have been reported recently ${ }^{6,7}$.In this study, thoracobifemoral bypass grafting with the novel anterior subcutaneous approach was proposed.

Thoracofemoral bypass has major advantages over axillofemoral bypass because it provides better inflow, requires a shorter graft length, offers better protection of the graft from infection and mechanical trauma, and carries a superior patency rate.The descending thoracic aorta typically has minimal atherosclerotic disease, which makes it more suitable for proximal anastomosis than the infrarenal aorta. Thoracofemoral bypass was first described by Blaisdell and colleagues $^{8}$ as an alternative to standard aortofemoral bypass. Subsequently, several groups have recommended this technique as an alternative or first-choice procedure for aortoiliac occlusion ${ }^{9,10}$. In fact, long-term follow-up studies have documented excellent patency rates. Criado and colleagues ${ }^{11}$ described 16 cases that in addition to those reported in the English language literature, gave a combined surgical mortality rate of $6.4 \%$ and the life-time primary graft patency was $98 \%$ at 1 year, $88 \%$ at 2 years, and $70.4 \%$ at 5 years.In this study, the mortality rate was $6.3 \%$ with $87 \%$ of patients doing well in follow up.

Bypass grafting from the descending thoracic to iliac or femoral arteries traditionally has been reserved for patients with aortic graft failure or infection or as an alternative procedure when a direct transabdominal aortic approach is not feasible. Despite use as a remedial operation, previously published results have been satisfactory, with patency rates that ranged from $76 \%$ to $86 \%$ at 5 years ${ }^{12,13,14,15,16}$

Although the role of descending thoracic aorta-to-iliofemoral artery bypass grafting is well established as a secondary procedure, its use as a primary operation is controversial. In selected patients in whom unfavorable abdominal conditions (eg, prior multiple abdominal surgeries, radiation, or intraabdominal sepsis) make the approach to the infrarenal aorta difficult, primary descending thoracic aorta-to-iliofemoral artery bypass grafting is a better option.In this technique, descending thoracic aorta bypass grafting was done as primary procedure in patients with infrarenal aortic block with no site for aortic clamping, calcified aorta and past history of previous laparotomy.

The proposed mechanism for infrarenal aortic occlusion is that of iliac and distal aortic atherosclerotic disease progression and subsequent infrarenal aortic thrombosis, with outflow to the renal arteries maintaining patency of the suprarenal aorta. Several reports have raised concern for proximal aortic thrombus propagation manifested as renal dysfunction or mesenteric compromise ${ }^{17,18}$. Although we did not routinely obtain follow up aortic imaging to assess for suprarenal propagation of thrombus after descending thoracic aorta-to-iliofemoral artery bypass grafting, late renal failure did not develop in any of the patients.

In conclusion, descending thoracic aorta-to-iliofemoral artery bypass grafting has excellent overall long term results. This supports its continued use as an alternative procedure for aortic graft failure or infection. A more liberal use for primary revascularization also should be considered for patients with severe atherosclerotic disease, complete occlusison of the infrarenal aorta, calcified aorta and past history of previous laparotomy, especially when a direct transabdomial approach is not feasible. 


\section{References}

[1]. JK Stevenson, LR Sauvage, HN. Harkins -A bypass homograft from thoracic aorta to femoral arteries for occlusive vascular disease, Am Surg, 27 (1961), pp. 632-637.

[2]. FW. Blaisdell -Extraperitoneal thoracic aorta to femoral bypass ,Am J Surg, 102 (1961) pp.83-85

[3]. E Criado, G Johnson Jr, SJ Burnham et al. -Descending thoracic aorta-to-iliofemoral artery bypass as an alternative to aortoiliac reconstruction, J Vasc Surg, 15(1992),pp550-557.

[4]. E Criado, BA. Keagy -Use of the descending thoracic aorta as an inflow source in aortoiliac reconstruction: indications and longterm results, Am Vasc Surg,8(1994),38-47.

[5]. J Ligush Jr, E Criado, SJ Burnham et al. -Management and outcome of chronic atherosclerotic infrarenal aortic occlusion, J Vasc Surg, 24 (1996), pp. 394-405.

[6]. Passman MA, Taylor LM, Moneta GL, Edwards JM, Yeager RA, McConnell DB, et al. Comparison of axillofemoral and aortofemoral bypass for aortoiliac occlusive disease. J Vasc Surg 1996;23:263-71

[7]. Mii S, Mori A, Sakata H, Kawazoe N. Fifteen-year experience in axillofemoral bypass with externally supported knitted Dacron prosthesis in a Japanese hospital. J Am Coll Surg 1998;186:581-8.

[8]. Blaisdell FW, McMattei GA, Gauder PJ. Extraperitoneal thoracic aorta bifurcation prosthesis: case reports. Am J Surg 1961;102:583-5.

[9]. McCarthy WJ, Mesh CL, McMillan WD, Flinn WR, Pearce WH, Yao JS. Descending thoracic aorto-to-femoral artery bypass: 10 years' experience with a durable procedure. J Vasc Surg 1993;17:336-48.

[10]. Branchereau A, Magnan PE, Moracchini P, Espinoza H, Mathieu J. Use of descending thoracic aorta for lower limb revascularization. Eur J Vasc Surg 1992;6:255-62.

[11]. Criado E, Johnson G Jr, Burnham SJ, Buehrer J, Keagy BA. Descending thoracic aorto-to-iliofemoral artery bypass as an alternative to aortoiliac reconstruction. J Vasc Surg 1992;15:550-7.

[12]. RJ Feldhaus, AV Sterpetti, RD Shultz et al. -Thoracic aorta-femoral bypass: indications, technique, and late results, Ann Thorac Surg, 40 (1985), pp. 588-592.

[13]. DE Bowes, JR Youkey, WP Pharr et al.- Long term follow-up of descending thoracic aorto-iliac/femoral bypass, J Cardiovasc Surg, 31 (1990), pp. 430-437.

[14]. A Branchereau, PE Magnan, P Moracchini et al.- Use of descending thoracic aorta for lower limb revascularization, Eur J Vasc Surg, 6 (1992), pp. 255-262.

[15]. WJ McCarthy, CL Mesh, WD McMillan et al.- Descending thoracic aorta-to-femoral artery bypass: ten years' experience with a durable procedure, J Vasc Surg, 17 (1993), pp. 336-348.

[16]. P Sapienza, A Mingoli, RJ Feldhaus et al.- Descending thoracic aorta-to-femoral artery bypass grafts, Am J Surg, 174 (1997), pp. 662-666.

[17]. RW Starrett, RJ. Stoney- Juxtarenal aortic occlusion, Surgery, 76 (1974), pp. 890-897.

[18]. GP Deriu, E. Ballotta- Natural history of ascending thrombosis of the abdominal aorta, Am J Surg, 145 (1983), pp. $652-657$ 